\section{A produção da Associação dos Geógrafos Brasileiros em meados do século XX e os estudos da Geografia do Rio Grande} do Sul

\begin{abstract}
RESUMO: O trabalho reporta-se ao levantamento da produção sobre a Geografia do Rio Grande do Sul, veiculada nas assembléias da Associação dos Geógrafos Brasileiros - AGB, durante as décadas de 1940, 1950 e 1960 e conta com apoio do BIC-Fapergs. É fruto de um projeto de identificação e localização dos documentos apresentados e produzidos nas distintas assembléias realizadas no período, que dizem respeito ao Estado do Rio Grande do Sul, em especial sua região central. Para o presente artigo serão apresentados os trabalhos inventariados, a partir das publicações e da produção dos geógrafos de meados do século $X X$, vinculados aos eventos da AGB.
\end{abstract}

\section{The production from Association of Brazilian Geographers in the middle of 20th century and the studies of Rio Grande do Sul Geography}

\begin{abstract}
The paper refers to a survey of the production on Rio Grande do Sul Geography, presented at assemblies from Association of Brazilian Geographers - AGB, during 1940s, 1950s and 1960s and is supported by BIC-Fapergs. It resulted from a project of identification and localization of the documents presented and produced in several assemblies carried out in the period, which regards to Rio Grande do Sul State, in especial, its central region. For the current article, are presented the papers found, from the publications and productions of geographers from the middle of 20th century, articulated to AGB events.
\end{abstract}

\section{Eduardo Schiavone Cardoso* Samanta Diuli Altermann** Marcelo Bêz ${ }^{* * *}$ Bruna Camila Dotto****}

*Professor Associado do Departamento de Geociências - UFSM **Acadêmica do Curso de Geografia - UFSM. Bolsista Probic-Fapergs ***Mestrando - PPGGEO - UFSM ****Acadêmica - Curso de Geografia - UFSM

Palavras-chave: Geografia; Rio Grande do Sul; AGB; Memória. Key-words: Geography; Rio Grande do Sul; AGB; Memory. 


\section{Introdução}

A proposta do trabalho consiste na sistematização e análise dos documentos apresentados e produzidos nas Assembléias Ordinárias da Associação dos Geógrafos Brasileiros - AGB, realizadas nas décadas de 1940, 1950 e 1960, buscando sua difusão, enquanto fontes de pesquisa para o entendimento das temáticas que versem sobre o Estado do Rio Grande do Sul, em especial sua região central.

São três os objetivos do trabalho:

1)Localizar e inventariar a produção sobre 0 Rio Grande do Sul, veiculadas nas Assembléias da Associação dos Geógrafos Brasileiros nas décadas de 1940, 1950 e 1960;

2)Realizar fichas de identificação dos trabalhos localizados e uma descrição preliminar dos temas desenvolvidos;

3) Sistematizar e disponibilizar o acervo desenvolvido durante o projeto.

Os acervos e anais das Assembléias da Associação dos Geógrafos Brasileiros das décadas de 1940 a 1960, estão locados, em parte, na Biblioteca da AGB em São Paulo, bem como nos acervos de outras instituições. Uma parte deste material, dentre eles os anais da XIII Assembléia Geral Ordinária da Associação dos Geógrafos Brasileiros, ocorrida em 1958 na cidade de Santa Maria, foi organizada por Dora de Amarante Romariz, sendo publicados pela AGB em tomos e volumes.Também foram publicados trabalhos avulsos, referentes aos resultados dos relatórios das pesquisas de campo realizados durante as assembléias. A figura 1 apresenta a reprodução da capa de um dos volumes dos anais, apresentando a identidade visual adotada pela entidade em seus primórdios de atuação.

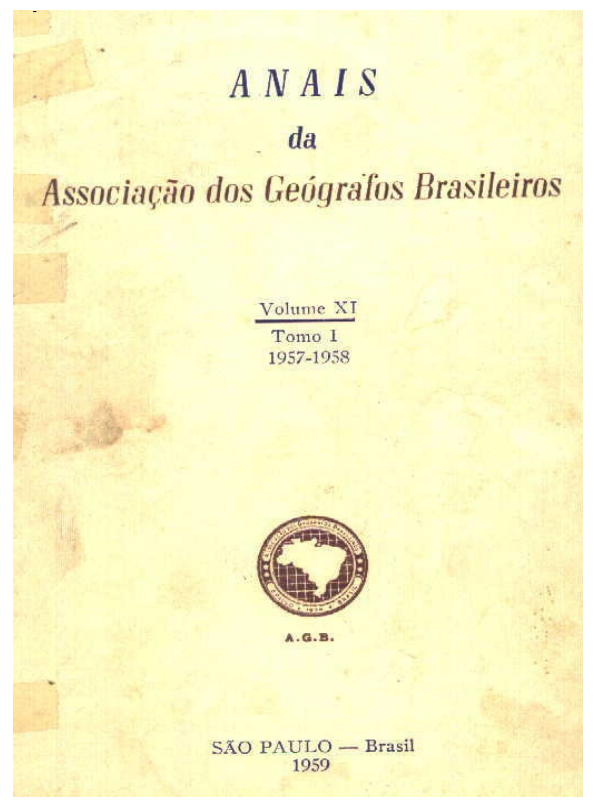

Figura 1 - Imagem de volume publicado referente aos Anais da AGB

\section{A produção inventariada}

Geografia Ensino \& Pesquisa, v. 15, n.3, p. 217 226, set./dez. 2011

A produção da Associação dos Geógrafos Brasileiros em meados do século XX e os estudos da Geografia do Rio Grande do Sul
Na primeira fase da pesquisa foram identificados e analisados documentos oriundos de pesquisas e trabalhos de campo referentes ao Estado do Rio Grande do Sul, produzidos por geógrafos e demais pesquisadores, brasileiros e estrangeiros, dentre os quais Nice Lecocq Müller, Aroldo de Azevedo, Jean Roche, Jorge Chebataroff. 
Seis desses artigos estão presentes nos distintos volumes dos Anais das Assembléias das AGB, ao passo que o relatório intitulado A Região de São Gabriel, foi publicado como Avulso n. 4, em 1962 pela AGB e consta do resultado dos trabalhos de campo realizados sob a coordenação de Nice Lecocq Müller na Campanha Gaúcha, durante a Assembléia de 1958, realizada na cidade de Santa Maria.

Os textos foram obtidos a partir de cópias das publicações localizadas nas bibliotecas da Faculdade de Filosofia, Letras e Ciências Humanas da Universidade de São Paulo - FFLCH - USP e da Seção São Paulo da AGB. Os trabalhos de Antunes (2008) e Monteiro (2002) serviram como referenciais para a recomposição histórica dos eventos promovidos pela AGB no período estabelecido para a pesquisa.

A perspectiva do projeto é realizar a identificação e contribuir na difusão dessas fontes de pesquisa, de modo a apresentar o papel da Associação dos Geógrafos Brasileiros como uma instância de produção de conhecimento em suas décadas de existência. $O$ quadro a seguir identifica os trabalhos levantados, respectivos autores e dados de identificação bibliográficos.

\begin{tabular}{|c|}
\hline - AS PAISAGENS DO RIO GRANDE DO SUL (IMPRESSÕES DE VIAGEM) - Aroldo de Azevedo \\
\hline $\begin{array}{l}\text { - Assembléia /data/ local- VII ASSEMBLÉIA GERAL ORDINÁRIA DAASSOCIAÇÃO DOS GEÓGRAFOS BRASILEIROS - } \\
\text { Campina Grande/ Paraiba } 1952\end{array}$ \\
\hline - Referência da publicação dos anais - Anais da AGB,volume VI ,tomo I, São Paulo,1954. \\
\hline - REGIONES NATURALES DE RIO GRANDE DEL SUR Y DEL URUGUAY - Jorge Chebataroff \\
\hline $\begin{array}{l}\text { - Assembléia/ data / local- VII ASSEMBLÉIA GERAL ORDINÁRIA DAASSOCIAÇÃO DOS GEÓGRAFOS BRASILEIROS - } \\
\text { Campina Grande/ Paraiba } 1952\end{array}$ \\
\hline - Referência da publicação dos anais - Anais da AGB volume VI, tomo I ,São Paulo,1954. \\
\hline - CONTRIBUIÇÃO AO ESTUDO DA CAMPANHA GAÚCHA - Miguel Alves de Lima \\
\hline $\begin{array}{c}\text { 7-Assembléia /data/ local- I CONGRESSO BRASILEIRO DE GEÓGRAFOS / IXASSEMBLÉIA GERAL DAASSOCIAÇÃO } \\
\text { DOS GEÓGRAFOS BRASILEIROS - Ribeirão Preto/São Paulo - } 1954\end{array}$ \\
\hline - Referência da publicação dos anais- Anais da AGB ,volume VIII, tomo I, São Paulo 1956. \\
\hline - PRADERAS DE LAAMÉRICA DEL SUR TEMPLADA - Jorge Chebataroff \\
\hline $\begin{array}{l}\text {-Assembléia/ data/ local- XIII ASSEMBLÉIA GERAL DA ASSOCIAÇÃO DOS GEÓGRAFOS BRASILEIROS - Santa Maria/ Rio } \\
\text { Grande do Sul, } 1958\end{array}$ \\
\hline - Referência da publicação dos anais-Anais da AGB, volume XI, tomo I, São Paulo, 1959 \\
\hline -AREGIÃO DE SÃO GABRIEL - Nice Lecocq Müller \\
\hline $\begin{array}{c}\text {-Assembléia/data/ local - Relatório de TRABALHO DE CAMPO realizado durante a XIII ASSEMBLÉIA GERAL DAASSOCIAÇÃO } \\
\text { DOS GEÓGRAFOS BRASILEIROS - Santa Maria/ Rio Grande do Sul, } 1958\end{array}$ \\
\hline - Referência da publicação - Avulso № 4 da AGB, São Paulo, 1962. \\
\hline - A CONTRIBUIÇÃO DA COLONIZAÇÃO ALEMÃ À VALORIZAÇÃO DO RIO GRANDE DO SUL \\
\hline - Jean Roche \\
\hline $\begin{array}{l}\text { - Assembléia/ data/ local- SIMPÓSIO COLONIZAÇÃO E VALORIZAÇÃO REGIONAL na XVI ASSEMBLÉIA GERAL DA } \\
\text { ASSOCIAÇÃO DOS GEÓGRAFOS BRASILEIROS - Londrina/Paraná em } 1961\end{array}$ \\
\hline - Referência da publicação dos anais- Anais da AGB , volume XIV, São Paulo, 1968. \\
\hline -A VEGETAÇÃO DA FAIXA COSTEIRA SUL-RIO-GRANDENSE - Ir. Juvêncio \\
\hline $\begin{array}{l}\text { - Assembléia data local- XVI ASSEMBLÉIA GERAL DA ASSOCIAÇÃO DOS GEÓGRAFOS BRASILEIROS - Londrina/Paraná } \\
\text { em } 1961\end{array}$ \\
\hline - Referência da publicação dos anais- Anais da AGB , volume XIV, São Paulo, 1968. \\
\hline
\end{tabular}

Geografia Ensino \& Pesquisa, v. 15, n.3, p. $217-$ 226, set./dez. 2011

Cardoso, E. S.; Altermann, S. D.; Bêz, M.; Dotto, B. C.

Quadro 1 - Produção inventariada 


\section{Sinopse dos artigos levantados}

Com a perspectiva de apresentar uma primeira amostra do material inventariado, as sinopses a seguir informam ao leitor os assuntos tratados nos artigos apresentados nas Assembléias da AGB, referentes às distintas temáticas e processos naturais e socioeconômicos do Rio Grande do Sul. Na medida das informações presentes nos trabalhos, foram destacados os momentos e os motivos em que tais pesquisas foram realizadas.

0 projeto tem a finalidade de apresentar os artigos na íntegra, contribuindo para sua divulgação e possibilitando a análise por parte dos interessados. Para tanto os esforços iniciais estão sendo desprendidos. No momento, o objetivo das sinopses é o de apresentar as obras em seus aspectos mais genéricos.

\section{As paisagens do Rio Grande do Sul (Impressões de viagem) Aroldo de Azevedo}

O artigo foi produzido a partir de uma viagem de campo executada durante a "Semana de Estudos Geográficos", organizada pela Faculdade de Filosofia da Universidade Católica do Rio Grande do Sul, no mês de outubro de 1951, Este trabalho de campo teve duração de duas semanas, e devido ao reduzido tempo não foi possível relatar mais do que simples impressões de viagem. O objetivo deste estudo é simplesmente transmitir uma parcela do encantamento que as áreas percorridas despertaram nos cientistas, utilizando-se de observações e fotografias.

A primeira região descrita é a do Guaíba e o delta do Jacuí, onde situa-se a cidade de Porto Alegre ligada ao chamado Rio Guaíba. A capital do estado do Rio Grande do Sul nasceu às suas margens há mais de dois séculos e viveu sempre em função dele, quer para contatos com 0 exterior (através das águas da Lagoa dos Patos), quer para comunicação com o "hinterland" gaúcho (através do vale do Jacuí). 0 Guaíba continua sendo a base de sua expansão, pois os subúrbios mais procurados acompanham as águas fluviais numa extensão de cerca de $40 \mathrm{Km}$.

A segunda região descrita corresponde aos grandes horizontes da Depressão Central, o estuário do Guaíba e o delta interior do Jacuí constituem a "sala de entrada" da chamada Depressão Central do Rio Grande do Sul, também chamada de Depressão do Jacuí. Esta depressão é caracterizada por um relevo de altitudes modestas e pela presença da planície fluvial, do que resulta uma notável extensão dos horizontes. Outra característica importante é a existência de intermináveis campinas, onde predomina a criação extensiva de gado.

Como terceira região tem-se a "Zona da Mata" do Rio Grande do Sul, sendo que a floresta surge na encosta e no próprio Planalto arenito-basáltico. A transição entre a Depressão e 0 Planalto faz-se de maneira relativamente suave: formada por esporões montanhosos com altitudes médias de 300 metros, que constituem as chamadas "serras" de Botucaraí e São Martinho.

A quarta região são os grandes horizontes do Planalto, que se trata de um divisor de águas entre as bacias dos rios Uruguai e Jacuí, tendo uma topografia levemente ondulada e apresentando com frequencia as depressões rasas: os "banhados". Possui uma rede de drenagem escassa e o predomínio de vegetação rasteira, denunciando um solo pobre e impermeável, sendo que as árvores aparecem como verdadeiras exceções.

A produção da Associação dos Geógrafos Brasileiros em meados do século XX e os estudos da Geografia do Rio Grande do Sul 


\section{Regiones Naturales de Rio Grande Del Sur Y Del Uruguay Jorge Chebataroff}

Este artigo é resultado de diversas viagens de campo realizadas pelo autor aos mais distintos lugares do Uruguai, coleções de materiais geológicos e botânicos, apontamentos de viagens e grande número de fotografias, além do apoio de alguns especialistas de disciplinas científicas. $\mathrm{O}$ zoneamento que Chebataroff propôs se baseia principalmente nas particularidades do relevo e das formações vegetais, levando em consideração os tipos de solo e as influencias de ordem microclimáticas e como estas influenciam diretamente sobre a atividade humana. 0 autor introduz o conceito de penillanura como uma característica geomorfológica dominante na porção sul e central do Rio Grande do Sul e de grande parte do Uruguai, eliminando conceitos duvidosos como "campinas", "campos", "região ondulada", "altiplano de Haedo", "escudo riograndense", que tem valor somente local, ou baseadas em formações geológicas.

Por fim, pode-se considerar que se trata de um texto rico em detalhes físicos no que diz respeito às regiões naturais do Rio Grande do Sul, do Uruguai e da Argentina, que nas palavras do autor possuem poucas diferenças entre elas. Estas regiões naturais não respeitam limites políticos e institucionalmente estabelecidos, estabelecendo continuidades no que diz respeito à fauna, flora, solos e climas, mostrando uma similaridade entre os biomas do Rio Grande do Sul, do Uruguai e da Argentina.

\section{Contribuição ao Estudo da Campanha Gaúcha Miguel Alves de Lima}

O estudo é resultado de um longo trabalho de campo que objetivou o reconhecimento da Campanha Gaúcha, mais especificamente na parte sudoeste do estado do Rio Grande do Sul, pelo autor entre os meses de setembro a outubro de 1953. Nesta viagem de campo foram percorridos 16 municípios, totalizando cerca de $2.500 \mathrm{~km}$ de rodagem.

No item aspectos do relevo 0 autor descreve as formações sedimentares da zona sudoeste da Campanha Gaúcha e os derrames de lava, correspondendo a um relevo de "mesas e tabuleiros" e também um relevo de cuestas típicas. Diferentemente de outros autores, que trazem o relevo de uma forma generalizada, como se toda a topografia da Campanha Gaúcha fosse formada por campos abertos e coxilhas, Miguel Alves de Lima, procura demonstrar a distribuição e a correlação entre o relevo e a estrutura da zona.

As particularidades climáticas da Campanha Gaúcha partem de uma caracterização como sub-tropical, semi-úmido, com chuvas regularmente distribuídas, assinalando um máximo de precipitações no inverno. Como se trata de uma faixa de transição para um clima verdadeiramente temperado, esta área está sujeita a manifestações irregulares dos centros de ação climática vizinhos.

A vegetação do sudoeste do estado não pode ser descrita de maneira uniforme, pois considera 0 autor que o tipo de vegetação está ligado ao solo e rocha matriz, destacando as boas e as más pastagens e caracterizando cada um dos tipos existentes.

Nos aspectos referentes a economia tem-se o domínio da criação bovina, com uma crescente e expressiva criação de ovelhas, pois estas são menos exigentes quanto as pastagens. 0 autor apresenta dados referentes aos rebanhos e a lã, além de conseguir explicar o crescente

Geografia Ensino \& Pesquisa, v. 15, n.3, p. 217226, set./dez. 2011

Cardoso, E. S.; Altermann, S. D.; Bêz, M.; Dotto, B. C. 
${ }^{1}$ Orientadora das pesquisas de campo realizada na região de São Gabriel. Participaram também Lysia Maria Cavalcanti Bernardes, Cecilia França, Michel Tabuteau, Antônio Rocha Penteado que se encarregaram da direção dos grupos de trabalho. Dentro dos vários grupos, cumpriram suas tarefas com louvável dedicação: Alba Maria Baptista Gomes, Lília Veiran, Marly Bustamante, Olga Cruz, Olga Ramos, Palmira Monteiro, Ruth Simões, Edgar Kuhlmann, Éli Piccolo, Francisco Takeda, Ignácio Takeda, Irmão José 0. Goettert e Rauquírio Marinho. desenvolvimento da criação de ovinos, em contraste com a retração da cultura bovina. Tal fenômeno é relacionado com a procura crescente da lã no mercado consumidor, além de demonstrar dados que relatam o crescimento da produção de lã em alguns municípios gaúchos durante o período de 1920 a 1950.

\section{Praderas de la América Del Sur Templada Jorge Chebataroff}

O presente estudo teve como finalidade reconhecer e cartografar os diversos tipos de vegetação, visando preparar um mosaico ou mapa da região em questão, nas quais figuram representadas as áreas ocupadas por massas arbóreas, as arbustivas, as de pradarias, as mistas, etc. Este trabalho foi facilitado pela utilização de fotografias ou a simples inspeção aérea, ambas em voga na época. Resultou-se indispensável realizar também observações e estudos no terreno, que sempre conduzem a resultados mais seguros e decisivos.

No final do artigo é feita uma caracterização densa das pradarias da Província Uruguaia, quanto aos tipos de vegetação existentes nos distritos integrantes desta. Para identificar alguns tipos de vegetação herbácea o autor utiliza-se de alguns métodos, como por exemplo o método do quadrado, onde o mesmo realiza o estudo das pastagens da serra Mahoma.

\section{A região de São Gabriel ${ }^{1}$ Nice Lecocq Müller (coord.)}

Esta pesquisa é resultado do trabalho de campo realizado no decorrer da XIII Assembléia Geral da Associação dos Geógrafos Brasileiros, entre os dias 7 e 9 de julho, na região de São Gabriel, na Campanha Gaúcha. Todas as informações foram levantadas a partir de observações e inquéritos, dispondo de dados estatísticos e bibliográficos apenas para confirmar as hipóteses levantadas acerca dos problemas encontrados.

$\mathrm{Na}$ Campanha de São Gabriel predomina tipicamente o sistema de criação extensiva, o gado é criado solto em pastagens naturais, esta forma de pastoreio corresponde ao tipo clássico dominante na Campanha Gaúcha. A criação de ovino contribui para o desgaste das pastagens prejudicando ainda mais o problema da super-lotação dos pastos, constituindo verdadeiro problema da pecuária da região. Isto ocorre com criadores que dispõe de menor área ou que contam com pastos de má qualidade. 0 crescimento do rebanho ovino em relação ao bovino pode ser interpretado como uma espécie de resposta ao cansaço das pastagens, uma vez que os carneiros são menos exigentes em alimentação, sendo que, além do consumo da carne, a produção de lã aumentou consideravelmente entre os anos de 1950 e 1957.

Dos produtos agrícolas de maior significação econômica, o arroz é o de mais antiga cultura, devendo sua introdução na região datar da primeira década do século. A cultura do trigo em escala comercial começou no município há cerca de dez anos. De modo geral, as explorações ligadas ao trigo são muito maiores que as de arroz, isso ocorre pelo fato do trigo se tratar de uma cultura mecanizada em todas as suas fases, exigindo pequena mão-de-obra. Com uma produção crescente, o trigo representa o principal produto agrícola de São Gabriel.

A cidade de São Gabriel está localizada sobre uma elevação, esta se trata de uma "coxilha" de topo relativamente amplo, com altitudes de 110-120 metros. A cidade se apresenta como um
A produção da Associação dos Geógrafos Brasileiros em meados do século XX e os estudos da Geografia do Rio Grande do Sul
Geografia Ensino \& Pesquisa, v. 15, n.3, p. 217226, set./dez. 2011 
ponto de concentração de várias vias de circulação, ligando Bagé e Livramento em direção ao sul, a Rosário a oeste, a Santa Maria ao norte e a São Sepé a leste. São Gabriel, dentro da hierarquia das cidades gaúchas é apenas um "centro local", com modesta função de relação, servindo, basicamente, à área imediatamente vizinha.

Como centro de área pastoril, São Gabriel cresceu lentamente. Foi a partir de 1950, quando se desenvolveu a triticultura no município, que a cidade tomou impulso, expandindo-se. Com isso, multiplicaram-se as instituições cooperativas na cidade, contribuindo consideravelmente para mudar seu ritmo de vida e até mesmo seu aspecto.

\section{A contribuição da colonização alemã à valorização do Rio Grande do Sul Jean Roche}

O artigo traz um resgate histórico da colonização alemã no estado do Rio Grande do Sul, uma das mais antigas colonizações do Brasil, sendo datada de 1824, que teve com um dos principais objetivos povoar o sul do país com estrangeiros para reforçar a ocupação de uma província fronteiriça e introduzir pequenas propriedades numa região onde predominavam as grandes propriedades de origem lusa que obtinham seus recursos da criação extensiva.

Esses desbravadores contribuíram de forma significativa para a estruturação socioeconômica do estado e conquistando novos domínios, expandiram a área agricultável que foi imediatamente recompensado por uma valorização das terras. Se por um lado a agricultura alemã obteve ganhos através da abertura de áreas aráveis, por outro lado foram limitados pela lentidão do desenvolvimento dos meios de transportes e pela perda de produtividade das terras.

Pouco se retratou da cultura alemã como uma das influenciadoras da miscigenação cultural do Rio Grande do Sul, a qual é mais expressiva na metade norte do estado, sendo pouco significativa na região da campanha gaúcha, contudo, não deixa de ser um artigo rico para assuntos mais aprofundados no que diz respeito as instalações deste povo no estado juntamente com seus códigos culturais.

\section{A vegetação da faixa costeira sul-riograndense Ir. Juvêncio}

O autor classificou os agrupamentos vegetais Sul-Rio- Grandenses condicionados pelo clima, solo, e hidrologia local em quatro classes: a flora xeromorfa, a flora higrófila, a flora aquática ou hidrófila e a vegetação halófila. Sendo que estas classes são melhores descritas e caracterizadas no decorrer do texto.

llustrados com fotos representativas de cada uma destas classes, nas palavras do autor Irmão Juvêncio: "O litoral sul-rio-grandense, como se vê, não apresenta a suntuosidade florestal de outras regiões do território nacional, nem o número representativo de exemplares da flora, decididamente aborígenes e típicos." 


\section{Considerações}

A estratégia do projeto consiste em realizar o levantamento e a análise destes materiais, identificando artigos e passagens referentes ao Estado, de modo a sistematizá-los e disponibilizá-los sob a forma de uma publicação. Ao final do projeto espera-se fornecer 0 acesso a um suporte bibliográfico, produzido pelo trabalho de geógrafos de meados do século XX, para o desenvolvimento de novas pesquisas sobre a região central do Rio Grande do Sul, ampliando as possibilidades de investigação e tornando conhecidas estas fontes de informação.

Até o presente foram identificados os sete trabalhos descritos acima, relativos aos distintos aspectos da geografia do Rio Grande do Sul. Algumas considerações de caráter genéricas e observações preliminares, entretanto, podem ser tecidas.

A primeira refere-se aos distintos momentos, da dinâmica da AGB de então, em que tais trabalhos foram veiculados ou produzidos. Ainda que divulgados nos momentos das Assembléias Ordinárias anuais, algumas atividades complementavam esses momentos, tais como os simpósios, congressos e trabalhos de campo. Sendo assim, dos sete trabalhos elencados, um foi apresentado em um momento concomitante Assembléia/Congresso, um em um momento de Assembléia/Simpósio e um produzido durante os trabalhos de campo realizados na ocasião da Assembléia. Isso pode sugerir uma dinâmica de atividades de produção e divulgação do conhecimento geográfico, via AGB, que começa a sinalizar para as discussões mais específicas sobre as distintas temáticas - através dos simpósios, mesmo permanecendo momentos cujas temáticas trabalhadas eram de caráter mais variado.

A produção de um estudo, baseado em trabalhos de campo, realizados durante a Assembléia Geral é um outro fator a ser considerado. Além desse estudo, quase todos os demais dão ênfase em observações efetuadas em campo, demonstrando a importância dessa maneira de construção do conhecimento em Geografia.

Em alguns desses estudos fica claro o objetivo de apreensão dos fatos da natureza e da sociedade. Tal perspectiva, que podemos denominar de "clássica" - dentro dos estudos geográficos, acompanha três dos sete trabalhos selecionados. Nesse ponto chega-se a um terceiro ponto a considerar. Além de uma geografia mais geral, melhor dizendo regional, descritiva dos lugares e com forte aporte de observações de campo, aparecem nos quatro demais estudos, temáticas mais circunscritas, relativas à fitogeografia, geografia cultural e zoneamento do meio físico.

Finalmente, a participação e contribuição de pesquisadores estrangeiros nos eventos da AGB é um ponto a ser observado. Dentro do escopo de trabalhos elencados, dois são de autoria de Jorge Chebataroff e um de Jean Roche, versando sobre as temáticas mais circunscritas acima descritas.

O desenvolvimento do projeto permite cotejar os estudos produzidos e veiculados nos eventos dos primórdios da AGB e a Geografia contemporânea, auxiliando na construção do histórico das abordagens geográficas do Rio Grande do Sul, para melhor compreender, refletir ou aprimorar as perspectivas do pensamento geográfico. Apresenta a participação ativa da

Geografia Ensino \& Pesquisa, v. 15, n.3, p. 217226, set./dez. 2011

A produção da Associação dos Geógrafos Brasileiros em meados do século XX e os estudos da Geografia do Rio Grande do Sul
Associação dos Geógrafos Brasileiros em um dos momentos da construção do conhecimento geográfico brasileiro, que se projeta ainda hoje.

Com relação ao material pesquisado, sua divulgação pode fornecer suporte para a produção de novos estudos. A esse conjunto de considerações preliminares, espera-se 0 acréscimo de novas contribuições, à medida que tais trabalhos possam ser conhecidos. 


\section{Referências}

ANTUNES, Charlles da França. A Associação dos Geógrafos Brasileiros (AGB) - origens, idéias e transformações: notas de uma história. 2008, Tese (Doutorado em Geografia), Universidade Federal Fluminense, Niterói-RJ.

AZEVEDO, Aroldo de. "As paisagens do Rio Grande do Sul - Impressões de viagem". In ANAIS DA ASSOCIAÇÃO DOS GEÓGRAFOS BRASILEIROS, v. VI, t. I, 1954.

CHEBATAROFF, Jorge. "Regiones naturales de Rio Grande del Sur y del Uruguay". In: ANAIS DA ASSOCIAÇÃO DOS GEÓGRAFOS BRASILEIROS, v. VI, t. I, 1954.

CHEBATAROFF, Jorge. "Praderas de La América del Sur templada". In: ANAIS DA ASSOCIAÇÃO DOS GEÓGRAFOS BRASILEIROS, v. XI, t. I, 1958

IR. JUVÊNCIO. "A vegetação da faixa costeira sul-rio-grandense". In: ANAIS DA ASSOCIAÇÃO DOS GEÓGRAFOS BRASILEIROS, v. XIV, 1968.

LIMA, Miguel Alves de. "Contribuição ao estudo da Campanha Gaúcha". In: ANAIS DA ASSOCIAÇÃO DOS GEÓGRAFOS BRASILEIROS, v. VII, t. I, 1956.

MONTEIRO, Carlos Augusto Figueiredo. A Geografia no Brasil ao longo do século XX: um panorama. São Paulo: AGB-SP, 2002.

MÜLLER, Nice Lecocq (org.) "A região de São Gabriel”. In: AVULSO AGB, n. 4, 1962.

ROCHE, Jean. "A contribuição da colonização alemã à valorização do Rio Grande do Sul". In: ANAIS DA ASSOCIAÇÃO DOS GEÓGRAFOS BRASILEIROS, v. XIV, 1968. 